\title{
Reconceptualizing Political Knowledge: Race, Ethnicity, and Carceral Violence
}

\author{
Cathy J. Cohen and Matthew D. Luttig
}

\begin{abstract}
What is political knowledge? We argue that the traditional measure of political knowledge is limited, as it represents one domain of facts that people should know about American politics. This domain of knowledge is rooted in the liberal-democratic face of the state and neglects other political knowledge generated from the carceral face of the state. We argue that knowledge of carceral violence, especially against African Americans, represents a separate domain of knowledge that is particularly relevant to marginalized communities, especially black youth. Once we include carceral violence in our measures of political knowledge, established patterns of whites having more political knowledge than Blacks are reversed. Using a novel measurement strategy and based on a nationally representative survey of over 2,000 young people, we find that knowledge of carceral violence is distinct from measures of what has been called general political knowledge. Finally, we find that knowledge of carceral violence has distinct correlates from the standard knowledge battery and its relationship to political participation varies by racial group but tends to depress the political participation of African Americans. Our findings raise the question of what comprises relevant and important political knowledge today and for which communities.
\end{abstract}

$T$ he concept of political knowledge-most often defined as "the range of factual information about politics that is stored in long-term memory" (Delli Carpini and Keeter 1996, 10) - is central to research in public opinion and political behavior. Numerous studies find differences in political belief systems, the ability to hold elected officials accountable, and political participation rates between low- and high-knowledge respondents (e.g., Zaller 1992; Delli Carpini and Keeter 1996; Griffin and Flavin 2007; Ondercin and Jones-White 2011;
Brown and Bean 2016). Furthermore, the extent to which the public possesses political knowledge is often used as an evaluative criterion for general claims of civic competence. Specifically, those who possess more knowledge about national institutional politics, or what is often called general political knowledge, are presumed to be more informed, and therefore more politically competent than those who know less (but see Lupia 2016; Cramer and Toff 2017). Given the importance of the idea of general political knowledge, one worrying finding to emerge from

A list of permanent links to Supplemental Materials provided by the authors precedes the References section.

*Data replication sets are available in Harvard Dataverse at: https://doi.org/10.7910/DVN/IB504I

The authors thank the Youth and Participatory Politics Research Network supported by the MacArthur Foundation who secured the data featured in the paper, as well as Matthew Motta and Jon Rogowski for providing comments on earlier drafts of the manuscript.

Cathy J. Cohen is the David and Mary Winton Green Professor at the University of Chicago (cjcohen@uchicago.edu). She is the author of two books, The Boundaries of Blackness: AIDS and the Breakdown of Black Politics (University of Chicago Press, 1999) and Democracy Remixed: Black Youth and the Future of American Politics (Oxford University Press, 2010). She is also co-editor of the anthology Women Transforming Politics: An Alternative Reader (NYU Press, 1997) with Kathleen Jones and Joan Tronto. Her articles have been published in numerous journals and edited volumes including the American Political Science Review, NOMOS, GLQ, Social Text, and the DuBois Review.

Matthew D. Luttig is Assistant Professor at Colgate University (mluttig@colgate.edu). His articles have been published in numerous journals including Advances in Political Psychology; American Politics Research; Electoral Studies; Political Communication; Politics, Groups, and Identities; Public Opinion Quarterly; and Research and Politics. 
past research is that there are large group differences in knowledge levels (e.g., Verba, Schlozman, and Brady1995; Delli Carpini and Keeter 1996). Of central concern to us is the finding of differences across race and ethnicity in general political knowledge levels, and specifically that whites are thought to possess greater political knowledge than African Americans and Latinos.

We argue that race and ethnicity-based differences in political knowledge are biased by the types of political facts researchers ask in the measurement of the concept. Scholars have too often labeled a set of five to seven recall questions about national political offices and democratic processes general political knowledge (Delli Carpini and Keeter 1993, 1996). We want to be clear; we do not contest the definition of political knowledge as "the range of factual information about politics that is stored in longterm memory" (Delli Carpini and Keeter 1996, 10). Moreover, we believe there is insight to be gained from the use of scales that measure static general political knowledge of the national government, especially when researchers are interested in examining and predicting liberal-democratic process such as voting (Lupia 2016).

However, like other scholars we find such an approach to be limited in its understanding of the information that different communities need to be active participants in the political domain (Iyengar 1990; Krosnick 1990; Gilens 2001; Hutchings 2001; Kim 2009; Barabas et al. 2014). Specifically, we believe that general political knowledge questions get at how some people, some of the time, interact, engage with, and understand politics and government. But such questions do not do a good job of capturing the experiences of often marginalized communities who routinely interact with what scholars have called the carceral state or that face of the state focused on surveillance, criminalization, control and punishment (Weaver and Lerman 2010; Beckett and Murakawa 2012).

We therefore depart from previous research on political knowledge by arguing that past scholarship too often focuses on what Soss and Weaver (2017) describe as one "face" of the American state, the "liberal-democratic" face that emphasizes electoral-representative processes and conceives of the relationship between government and citizen as one in which citizens have extensive power and control. Most of this research assumes a political landscape where increases in either general or domainspecific knowledge lead to better political judgement that can be easily exercised in an open democratic process (Gilens 2001). Instead, we argue that the varied experiences with the state of marginal communities has generated a "range of factual information about politics" and governance that are significantly different than what is measured with general or domain-specific measures of the liberal arm of politics.

As has been documented elsewhere (e.g., Greenberg 1970; Abramson 1977; Cohen 2010; Hayward 2013; Soss and Weaver 2017), the experiences and socialization that poor communities of color have of and with government are fundamentally different. Significant numbers of people of color experience the government as a force that is "out to get them" (Cohen 2010, 151), not to represent them. For these communities, the state is too often perceived as an agent that actively exercises control through means of coercion and violence. And in this domain of state power, police and criminal justice institutions are front and center (Burch 2013; Lerman and Weaver 2014; Soss and Weaver 2017). This lived experience with the carceral state is all the more apparent today following the harrowing images that have spread-aided by social media-of police violence against African Americans in places like Ferguson, Baltimore, Chicago, and New York, and organizations and movements like the Black Lives Matter, BYP100, and the Movement for Black Lives that arose in the wake of such violence.

Consequently, we find that when looking at state violence against citizens, especially African Americansor what we call carceral violence-African Americans possess greater political knowledge of such acts than whites and therefore are not necessarily less politically knowledgeable overall, as the existing literature would suggest. Instead, we show that African Americans and whites possess different kinds of political knowledge. Furthermore, we show that knowledge of carceral violence has explanatory power on a variety of important political outcome variables such as political efficacy and engagement in protest activity over and above the traditional political knowledge scale for young Americans.

So if, as James David Barber argues, "citizens need to know what the government is and does" $(1973,44)$ and if Delli Carpini and Keeter are correct when they write that "much of what citizens are expected to do requires an understanding of the rules" (1996), then scholars need to understand that what the government does as well as the rules it plays by often vary by community. Moreover, if we as researchers are to fully understand how informed Americans are about politics or explain political engagement beyond voting (particularly for African Americans and Latinos), we need to include different measures of relevant political knowledge that get at the multiple ways in which citizens encounter, experience, and learn about the state and government (Barabas et al. 2014).

\section{Political Knowledge and the Carceral State}

Most scholars treat political knowledge or related constructs as a unidimensional concept. For example, Zaller $(1986,2)$ writes that "political information is a relatively general trait that can be effectively measured with a general-purpose information scale." Delli Carpini and Keeter also conceptualize political knowledge as a unidimensional concept, as their extensive analysis of general 
political knowledge leads them to conclude that most people are generalists when it comes to their knowledge about politics, and that for the vast majority of cases "a single common scale may suffice for valid measurement" (1996, 295).

However, many scholars have identified imperfections with this general concept and measurement of political knowledge. Even Delli Carpini and Keeter, in their analysis of gender gaps in political knowledge, acknowledge that "political knowledge is mostly_but not entirely - unidimensional. Some types of issues are of special relevance to certain groups, and some arenas of politics are more accessible to them" $(1996,209)$. This belief that some knowledge has greater relevance to distinct communities has led to a number of attempts to broaden the conception of political knowledge to include domainspecific questions (Kim 2009; Gilens 2001; Barabas et al. 2014) and questions relevant to identity-based groups such as women (Sanbonmatsu 2003; Dolan 2011) and specific racial and ethnic groups (Hutchings 2001; Pérez 2015).

These revised political knowledge questions, however, have largely stayed within the bounds of a liberal politics, focused on the rules, people, and parties in national political institutions. For example, Pérez's knowledge battery of Latino-themed political issues is specifically designed to "parallel traditional ones" (940), asking about Latino political figures and issues debated at the highest levels of the federal government. And Dolan's (2011) women-themed question set assesses knowledge about female politicians in national political institutions. Thus, the expanded set of questions considered by these scholars seem in many ways highly related to traditional or general knowledge questions.

Others have focused more squarely on identifying different types of political knowledge. Thus, some scholars draw a distinction between issue- or domainspecific and "general" knowledge (e.g., McGraw and Pinney 1990; Gilens 2001). Still other researchers point to the existence of issue publics or small pluralistic groups of individuals who are willing to expend resources to secure knowledge about an area or issue of importance to them (Converse 1964; Krosnick 1990; Kim 2009). Barabas et al. (2014) add to this scholarship the time horizon of a political fact, whether it reflects a recent issue/event or a static piece of information about American politics.

Research on domain-specific political knowledge suggests that individuals who do not know a great deal about the major political parties or how the Supreme Court functions or who holds specific political offices-those facts often measured as general political knowledge-may have greater knowledge about the domain-specific issues they care most about and that are perceived to most directly impact or threaten their lives and those with whom they identify (Iyengar 1990; Krosnick 1990;
Hutchings 2001; Prior 2002; Kim 2009). Scholars in this tradition make a distinction between individuals as generalist and specialists of political knowledge and are more apt to understand individuals as selectively making choices about the areas in which they will gather more knowledge. It is largely understood that such choices are motivated among other things by one's personal and collective interest, the direct impact of the information on one's life, and the availability of the information, as well as the timing of information. Borrowing from this approach, we expect that individuals from marginalized communities, especially those of color, will be particularly driven to acquire information about the carceral state, given their regular and negative interactions with this entity (Boninger et al. 1995; Kim 2012).

While we understand our current research to be very much in the tradition of the domain-specific and issue public literatures, we also note that our focus on the carceral state introduces at least two important differences. First and foremost, we believe that a focus on the carceral state changes the assumed relationship between political knowledge and political participation. Specifically, gaining greater expertise or political knowledge about the carceral state may work to depress engagement instead of encourage it. Most scholarship on domainspecific knowledge suggests that increased knowledge in any one area should lead to greater expertise and engagement in that area. For example, Ondercin and Jones-White, in their study of gender differences in political knowledge, found that "across all the acts of political participation we examined, more knowledgeable individuals were more likely to participate, regardless of sex" (2011, 690). However, we expect, as others have shown, that knowing about the repressive arm of the state may discourage people from engaging in politics, especially those forms of participation such as protest where one is more likely to directly encounter the police (Burch 2013; Lerman and Weaver 2014). Similarly, knowledge of carceral violence may decrease respondents' sense of external efficacy. Thus, given the heavy police presence in many marginalized communities of color, especially African American communities, and the often-negative interactions between officers and those same community members, we hypothesize that (1) African Americans will have greater knowledge of carceral violence than whites and possibly Latinos; and (2) that such knowledge will lower rates of political participation such as protest where one is more likely to encounter agents of the carceral state.

Second, a focus on the carceral state has implications for the types of facts scholars should consider when measuring political knowledge, especially if interested in public opinion and political behavior among African Americans. As discussed by Lupia (2016), despite the various additional political knowledge questions and scales that have been developed, many scholars continue to treat 
political knowledge as a general unidimensional construct. Facts about the carceral state, because they represent a separate face of the state from liberal-democratic processes, have the potential to reveal the multiple dimensions of political knowledge more clearly than other domainspecific measures of the liberal state.

In particular, our study highlights the importance of knowledge about the carceral state as facts that are somewhat distinct from facts about the liberal state that previous work on both general and domain-specific knowledge has mostly emphasized. Empirically, this expectation leads us to hypothesize that (3) information about the carceral state constitutes a separate domain of knowledge such that people who possess a lot of general political knowledge will not necessarily be the most knowledgeable about the carceral state, and vice versa; and (4) that knowledge of carceral violence will have distinct correlates from the general political knowledge scale. In the framework we propose, we measure one facet of knowledge about the state's carceral arm by asking respondents to identify victims of carceral violence. We understand that identifying victims of carceral violence represents some knowledge of carceral violence, but it cannot and is not intended to wholly encapsulate this construct.

Finally, social media is central to our understanding of the way information about the carceral state is disseminated. Specifically, we believe that social media can create spaces where youth of color, in particular, can access information on carceral violence. Here we are talking about websites that target communities of color, digital friendship networks dominated by other people of color, and platforms that allow for some identity-based exchange of information (i.e., Black Twitter). Research suggests that African American youth are poised to receive knowledge of carceral violence online, as they report using social media more than others as a means of connecting with family and friends, having more followers on Twitter and Facebook, and being more likely to create media for political means (e.g., Cohen and Kahne 2011; Perrin 2015). Thus, we hypothesize that (5) young people, in particular African American youth, who are active on social media, who visit websites targeting people of color, and who get news from social networks online are more likely to have knowledge of carceral violence.

\section{Data and Variables}

To measure and examine knowledge of carceral violence -and to compare this construct to the traditional conception of general political knowledge-we draw on data collected in Wave 3 of the Youth and Participatory Politics study commissioned in 2015. ${ }^{1}$ The survey is a nationally representative survey of young people, ages 15-29, and includes oversamples of both African
Americans and Latinos. The survey was administered by GfK based on two sources. The first source was GfK's probability-based Internet panel, and the second was a separate address-based sample (ABS). The addressbased sample was drawn from the U.S. Postal Service Delivery Sequence File in order to oversample African Americans and Latinos and was based on database sources believed to contain members of targeted racial or age groups. The GfK Internet panel also drew off of two sources: (1) a direct sample of 18-29 year olds, and (2) a sample of parents of persons aged 15-29. In the latter case, if the household did not have at least one person who was age- and race/ethnicity-eligible, the survey was terminated. Otherwise, one eligible household member was selected to participate. Of the total 2,772 sample size, 2,524 respondents came from GfK, 248 from ABS. All respondents took the survey using GfK's online platform. ${ }^{2}$

The survey included a 5-item measure of traditional or general knowledge based on the types of questions suggested by Delli Carpini and Keeter (1996). The questions are (1) which party has a majority of seats in the U.S. House of Representatives (majority party); (2) What majority is needed in the House and Senate to override a presidential veto (veto); (3) Which party is more conservative (conservative party); (4) Whose responsibility is judicial review (judicial review); and (5) What office is currently held by Joe Biden (Joe Biden).

To measure knowledge of carceral violence, we included 6 questions asking respondents to identify individuals who were either victims of police and state violence or entangled in what has been framed as discriminatory legal battles driven by the state. In all instances the events surrounding these cases were reported by the mainstream media to varying degrees. And while we recognize that the ability to identify African American victims of carceral violence does not fully operationalize the idea of carceral violence, these questions measure facts about recent cases of carceral violence that contrast with the static general political knowledge questions (see Barabas et al. 2014). This contrast in factual questions about the carceral state and liberal democratic state provides an opportunity for understanding the range and magnitude of difference in knowledge and impact between traditional and carceral measures of political knowledge. Our carceral violence questions were introduced with the following statement: "There have been a number of stories these days about confrontations between the police and citizens. Please match the name with the description of the person below." Respondents then received a list of six recent victims of carceral violence: Eric Garner, Michael Brown, Marissa Alexander, CeCe McDonald, John Crawford III, and Renisha McBride. We then provided respondents with the following brief descriptions and asked them to match the description to the correct individual. The order of the descriptions was randomized. 
(1) 43-year-old unarmed black male killed after being choked by police officer Daniel Pantaleo on July 17, 2014, in Staten Island, New York (Eric Garner).

(2) 18-year-old unarmed black male fatally shot by police officer Darren Wilson on August 9, 2014, in Ferguson, Missouri (Michael Brown).

(3) Black female sentenced to twenty years in prison for firing a "warning shot" following her husband attacking and threatening to kill her in Jacksonville, Florida (Marissa Alexander).

(4) black transgender woman convicted of second degree manslaughter after using deadly force to protect herself and friends from a physical, transphobic, and racist assault in Minneapolis, Minnesota, in 2012 (CeCe McDonald).

(5) 22-year-old black male fatally shot by police officers inside a Wal-Mart in Dayton, Ohio, on August 5, 2014 (John Crawford III).

(6) 19-year-old unarmed black female fatally shot in November 2013 after crashing her car and knocking on a stranger's door outside of Detroit, Michigan (Renisha McBride).

Table 1 presents the percentage of respondents who correctly answered each of the knowledge questions by race/ethnicity. This data provides an initial look at whether there are differences across race/ethnicity in knowledge of these questions. As expected, this table suggests important differences across the two types of knowledge: on average, whites answer more traditional knowledge questions correctly while African Americans do best answering questions about carceral violence victims. But this analysis does not tell us whether these differences across groups are statistically significant. This initial analysis also does not tell us whether these two domains of knowledge are highly

\begin{tabular}{|c|c|c|c|}
\hline & $\begin{array}{c}\text { African } \\
\text { Americans }\end{array}$ & Latinos & Whites \\
\hline Party Majority & 52 & 43 & 59 \\
\hline Veto Power & 40 & 32 & 58 \\
\hline Conservative Party & 49 & 54 & 78 \\
\hline Judicial Review & 62 & 62 & 74 \\
\hline Joe Biden & 83 & 70 & 92 \\
\hline Eric Garner & 76 & 53 & 65 \\
\hline Michael Brown & 82 & 68 & 84 \\
\hline John Crawford III & 63 & 42 & 51 \\
\hline Marissa Alexander & 50 & 35 & 39 \\
\hline CeCe McDonald & 53 & 36 & 42 \\
\hline Renisha McBride & 46 & 33 & 35 \\
\hline
\end{tabular}

correlated - that is, whether those who know a lot about traditional knowledge also know about victims of carceral violence.

\section{Group Differences in Political Knowledge Depend on Which Political Facts Are Measured}

Figure 1 shows that the group differences in traditional or general knowledge and knowledge of carceral violence are statistically significant at conventional levels. ${ }^{3}$ Whites score higher on measures of traditional knowledge (mean = 3.6) than both African Americans (mean = 2.9) and Latinos (mean $=2.6$ ). Figure 1 illustrates these differences and also shows that the difference between whites and African Americans, and between whites and Latinos, in traditional knowledge is statistically significant at a 95\% confidence level. African Americans are more knowledgeable about carceral violence $($ mean $=3.9)$ than whites (mean $=3.4$ ) and Latinos (2.9). Given that carceral violence is something experienced most by African Americans, we anticipated African American young people would be more interested in, receive more information, and possess more knowledge about victims of police and state violence than young whites or young Latinos. These results are robust in a model that includes potentially confounding demographic characteristics and differences in survey sample, such as education, age, sex, language of interview (English versus Spanish), marital status, employment status, region (South versus non-South), and sampling frame. In short, African Americans possess the greatest factual knowledge of the carceral state as measured in terms of victims of carceral violence while whites know most about the liberal state using the traditional general political knowledge questionnaire.

\section{Knowledge Differences across Items with Similar Measurement Properties}

One potential concern about our findings is that they may result, in whole or in part, from measurement invariance across groups. That is, knowledge differences may be an artifact of measurement rather than underlying differences between groups in factual information that is encoded and available in long-term memory. To address this concern, we analyzed item characteristic curves (ICC) for both traditional and carceral-violence knowledge from a two-parameter Item Response Theory (IRT) model for binary items to identify questions within both scales with similar measurement characteristics. IRT models provide information about the difficulty of different knowledge questions (indicated by the ability level at which the probability of getting a correct response is 0.5 ) and the extent to which different questions successfully discriminate between low and high levels of knowledge (indicated by the slope of the curve). Questions with a steeper slope indicate that the question better 


\section{Figure 1}

Group differences in traditional knowledge and knowledge of carceral violence

\section{Traditional Knowledge}
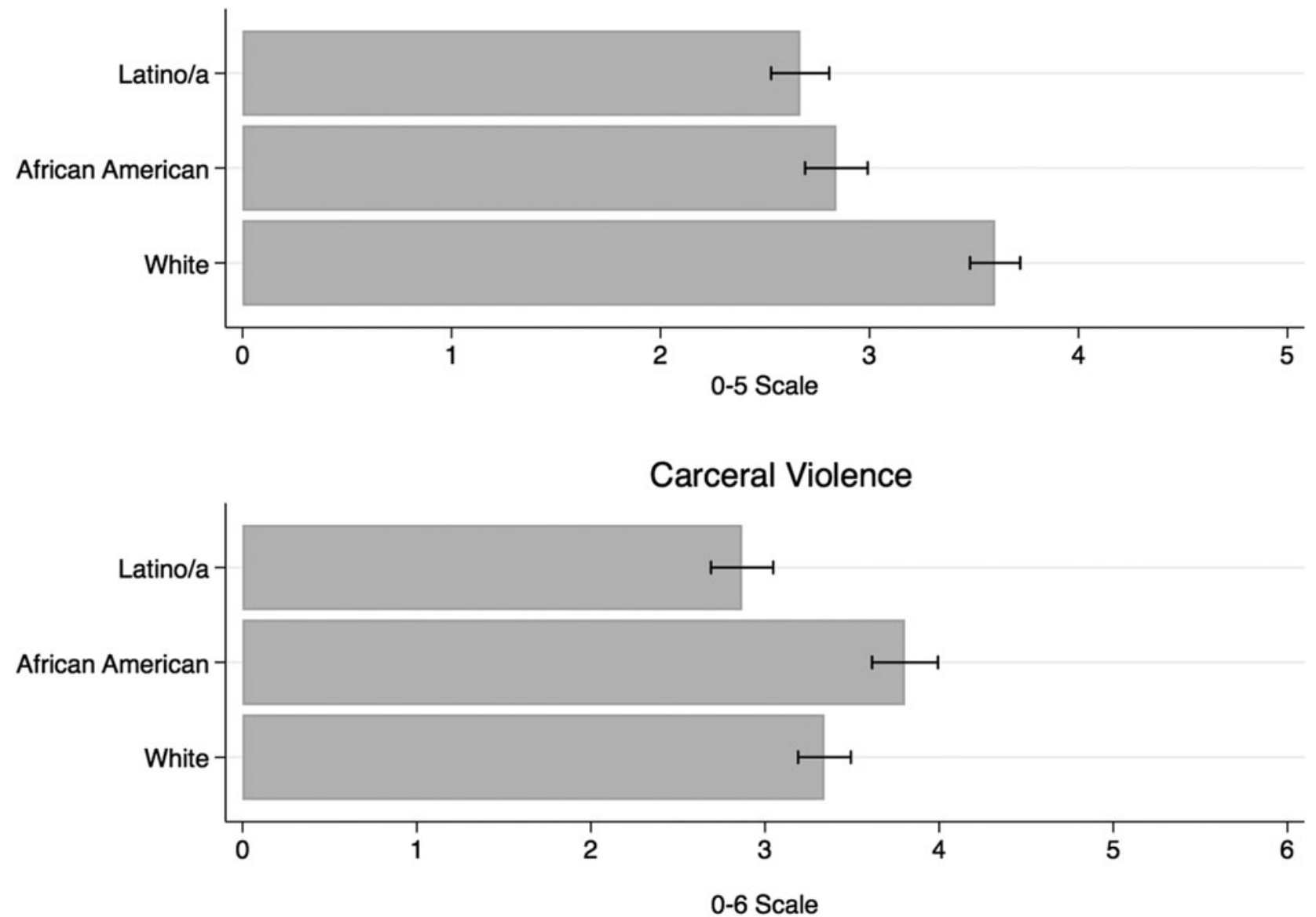

Note: Bars represent $95 \%$ confidence intervals.

discriminates between low and high knowledge respondents. The item characteristic curves are presented in online appendix Figures 1 and 2 (and online appendix Table 2 presents the direct difficulty and discrimination parameters represented in the ICC curves).

Overall, these figures show that each scale-and for each group-contains an appropriate mix of questions in terms of their difficulty. Questions that are difficult (e.g., knowledge of Renisha McBride) are difficult for everyone, while questions that are easier (e.g., knowledge of Michael Brown) are easier for everyone. Some questions do a very good job of discriminating between low- and highknowledge respondents. For example, knowledge of John Crawford III best discriminates low and high carceralviolence knowledge respondents among all groups. However, we find that the knowledge questions differ across groups in terms of their difficulty thresholds. The traditional knowledge questions are easier for white than for black and Latino respondents, and the carceral violence knowledge items are-with the exception of Michael Brown, which is actually easiest for whites-easier for African Americans than for white and Latino respondents. There is a mix of easy and difficult questions in both scales, and there are questions that effectively discriminate between low- and high-knowledge respondents.

Using this information, we identify questions with similar measurement properties for all groups and assess whether anticipated knowledge gaps continue to emerge. Here we present knowledge levels on two items from each scale which the IRT models suggest have similar measurement properties for all groups. For traditional knowledge, the two items are (1) knowledge of the majority party (which is the most similar traditional knowledge item across all racial/ethnic groups in its estimated difficulty) and (2) knowledge of Joe Biden (which is among the most effective items in discriminating between 
Figure 2

Group differences in knowledge of items with similar measurement properties
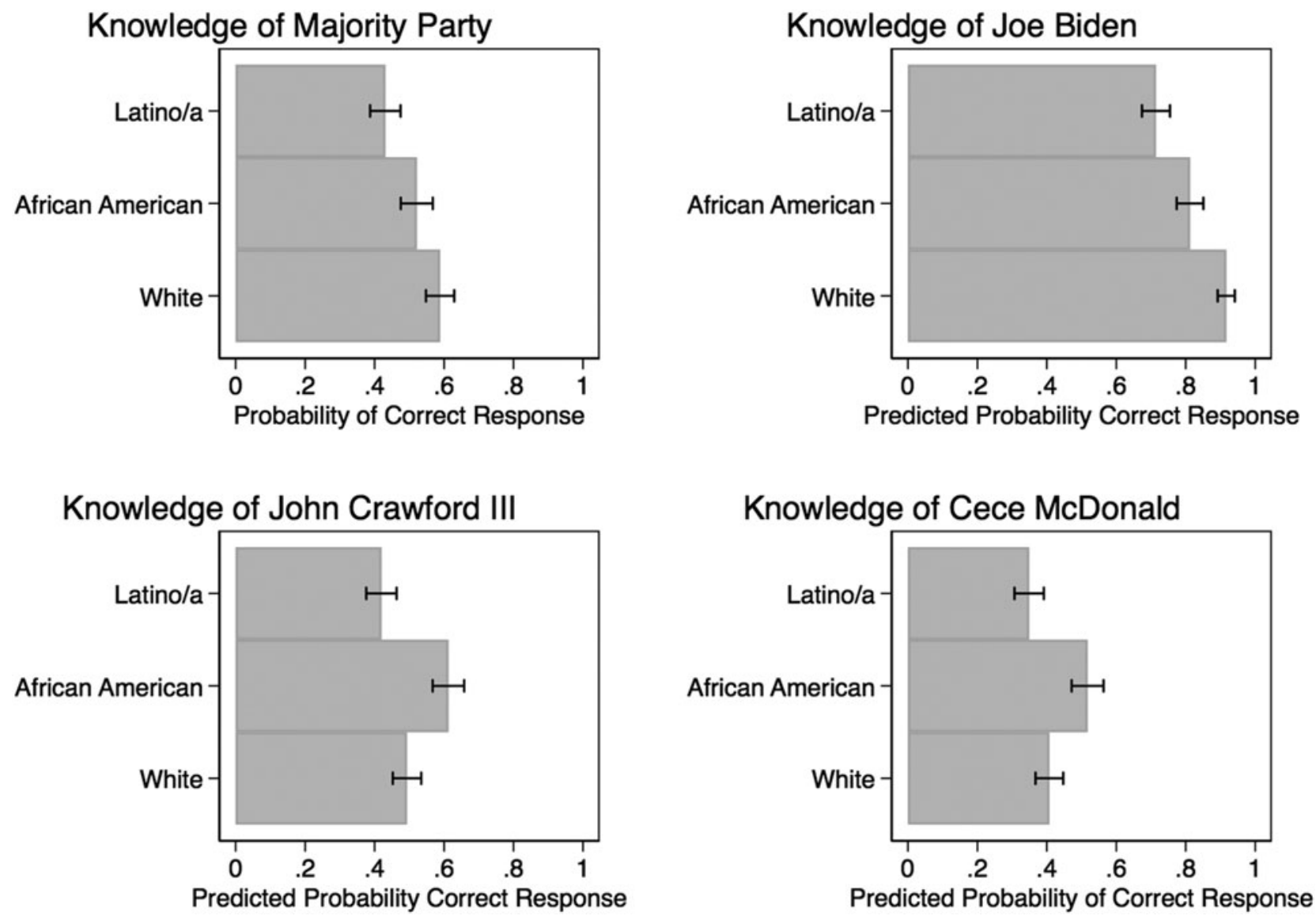

Note: Bars represent 95\% confidence intervals.

low- and high-knowledge respondents for all groups). For knowledge of carceral violence, the two items are (1) knowledge of John Crawford III (the item with the highest discrimination parameter for all groups and the most similar item in terms of its difficulty), and (2) knowledge of CeCe McDonald (the item with the second most-similar estimated difficulty for all racial/ethnic groups).

As Figure 2 shows, our analysis of knowledge items which the IRT suggests have similar measurement properties across racial/ethnic groups bolsters the findings presented in Figure 1: while whites possess the most information about items traditionally measured by the scale scholars have labeled "political knowledge" (knowledge of the majority party in Congress and the vice president at the time, Joe Biden), African Americans know the most about victims of carceral violence (John Crawford III and CeCe McDonald). Because these items perform similarly across racial/ethnic groups in terms of their difficulty and ability to discriminate low- from high- knowledge respondents, these findings strongly suggest that they reflect actual knowledge differences between groups and are not an artifact of extraneous measurement issues.

\section{How Much Overlap Exists between General Knowledge and Knowledge of Carceral Violence?}

We also conducted a series of correlational and factor analyses to assess the degree of overlap that exists between general knowledge and knowledge of carceral violence. As stated earlier, much of the literature on political knowledge in political science has used a general knowledge scale to encompass a wide variety of knowledge that citizens may possess on the assumption that people are generalists: those who know about these basic facts of the political landscape are likely to be most knowledgeable about other dimensions of government. However, research on domain-specific knowledge and issue publics present occasional evidence that challenges this assertion 
by showing that sometimes there are only weak correlations between general and issue- or group-specific knowledge. The unique contribution to this debate presented here is our focus on the carceral state. Do individuals who are well versed in the workings of the liberal state also know the most about the victims of the carceral state?

In the online appendix we present and discuss results from correlational analysis of individual items from both scales, exploratory and confirmatory factor analysis, and the correlation between latent variables for both traditional and carceral violence knowledge extracted from the IRT response models described earlier. From these analyses we conclude that there is limited overlap between knowledge of carceral violence and general political knowledge. For example, the correlation between latent variables of general political knowledge and knowledge of carceral violence extracted from the IRT models discussed above is just 0.32. People who know a lot about the traditional domain of politics do not necessarily know a lot about victims of carceral violence, while people who can identify victims of police and state violence do not necessarily possess high levels of knowledge about the parties and people that dominate national American electoral politics.

\section{Correlates of Different Types of Political Knowledge}

We next analyze correlates of these two types of political knowledge. To the extent that knowledge of carceral violence picks up a distinct though related domain of knowledge from the traditional knowledge scale, we expect to find some important differences in the correlates of these two types of knowledge. For example, while "traditional" knowledge may be learned in the classroom, we expect knowledge of carceral violence to be associated more with social interactions and the opportunity to learn this information through online discussions.

We examine the relationship between demographic predictors of political knowledge (e.g., sex, age), education, and the opportunity to learn about political facts afforded by the media and one's social surroundings. These predictors are widely used in analyses of traditional political knowledge. Thus, education is consistently a large predictor of traditional political knowledge, men are generally shown to exhibit greater traditional knowledge than women (but see e.g., Mondak and Anderson 2004; Prior 2013; Dolan 2011), individuals with greater opportunity to access political media have more traditional knowledge, and those with greater levels of political interest and who discuss politics also tend to possess the most traditional knowledge (see Delli Carpini and Keeter 1996, ch. 5). These predictors variously represent differences in ability, motivation, or opportunity to learn about politics (Luskin 1990; Delli Carpini and Keeter 1996). We hypothesize that all three factors should increase both general knowledge and knowledge of carceral violence. We also hypothesize that engagement with social media may enhance the opportunity for learning about carceral violence, as visceral images of police violence often spread first online and through social networks. Given that African Americans are highly digitally connected, spending more time on social media platforms and with more followers on platforms such as Facebook and Twitter (Cohen and Kahne 2011), we expect that getting news from social networks and frequency of Internet access may be especially predictive of knowledge of carceral violence for African Americans.

Table 2 presents an analysis of the following potential predictors, analyzed separately across racial and ethnic groups: education (on a 4-point scale from less than high school, high school, some college, BA degree+), age, sex $(1=$ female), Spanish, frequency of Internet use (how frequently an individual is online, from 0-7 days per week), the number of friends an individual has online, and online homophily (whether one interacts online primarily with members of one's racial/ethnic group). In the latter case, we expect that African Americans who communicate more with other African Americans will be exposed to and thus possess greater knowledge of carceral violence.

We also include a variable measuring the frequency with which a respondent visits websites targeting people of color. We expect to find a positive relationship between visiting websites targeting people of color and knowledge of carceral violence. We also include measures of how often the respondent discusses politics (both faceto-face and online) which should be associated with increases in political knowledge, much like political interest, which we also include. Finally, we include measures of how often respondents consume political media from different sources, including TV or radio, print newspapers or magazines, social media, or from various blogs and YouTube posts. Consistent with our theory that the new media landscape of the Internet and social media is central to dissemination of information about carceral violence, we expect that consuming political news from social media as well as blogs/YouTube posts will be most associated with knowledge of carceral violence, while consumption of news from TV and newspapers may be more strongly associated with traditional knowledge. All independent variables are dichotomous or on a $0-1$ scale, except for age which is kept in its original metric (15-29). Both dependent variables — a sum of the traditional political knowledge questions and a sum of the knowledge of carceral violence battery - are also rescaled to range from $0-1$.

A number of results in Table 2 are worth highlighting. First, education has a consistent and very large effect on the traditional political knowledge battery for all racial and ethnic groups. However, when it comes to knowledge of 
Table 2

Predictors of traditional knowledge and knowledge of carceral violence, by race and ethnicity

\begin{tabular}{|c|c|c|c|c|c|c|}
\hline & \multicolumn{2}{|c|}{ African Americans } & \multicolumn{2}{|c|}{ Whites } & \multicolumn{2}{|c|}{ Latinos } \\
\hline & $\begin{array}{l}\text { Traditional } \\
\text { Knowledge }\end{array}$ & $\begin{array}{c}\text { Knowledge } \\
\text { of Carceral } \\
\text { Violence }\end{array}$ & $\begin{array}{l}\text { Traditional } \\
\text { Knowledge }\end{array}$ & $\begin{array}{l}\text { Knowledge } \\
\text { of Carceral } \\
\text { Violence }\end{array}$ & $\begin{array}{l}\text { Traditional } \\
\text { Knowledge }\end{array}$ & $\begin{array}{c}\text { Knowledge } \\
\text { of Carceral } \\
\text { Violence }\end{array}$ \\
\hline ducati & $0.27^{\star \star}(0.05)$ & $0.17^{\star \star}(0.06)$ & $0.19^{\star \star}(0.05)$ & $0.15^{\star \star}(0.05)$ & $0.15^{\star \star}(0.05)$ & $0.04(0.06)$ \\
\hline Sex & & & -0.0 & & $-0 .(-1-x-1$ & \\
\hline Age & -0.02 & $-0 . c$ & $-0.01^{\star *}(0.00)$ & $-0.01^{\star \star}(0.00)$ & $-0.01 *(0.00)$ & $-0.00(0.00)$ \\
\hline Spanish & & & & & $-0.15^{\star \star}(0.04)$ & $-0.09^{* *}(0.04)$ \\
\hline $\begin{array}{l}\text { Frequency of Internet } \\
\text { Access }\end{array}$ & $0.17^{\star *}(0.08)$ & $0.19^{\star \star}(0.08)$ & $0.23^{\star \star}(0.08)$ & $0.08(0.07)$ & $0.21^{\star \star}(0.08)$ & $0.14^{*}(0.08)$ \\
\hline \# of Friends Online & $0.05)$ & $.06)$ & $-0.03(0.04)$ & $(0.04)$ & $0.03(0.05)$ & $0.01(0.05)$ \\
\hline Online Homophily & 0.00 & $0.06^{\star}(0.03)$ & $0.00(0.02)$ & $-0.04^{\star}(0.02)$ & $-0.08^{\star \star}(0.03)$ & $-0.06^{\star \star}(0.03)$ \\
\hline $\begin{array}{l}\text { Visiting Websites for } \\
\text { People of Color }\end{array}$ & $-0.04(0.04)$ & $-0.04(0.05)$ & $-0.09^{*}(0.05)$ & $-0.12^{\star \star}(0.06)$ & $-0.13^{\star \star}(0.05)$ & $-0.03(0.05)$ \\
\hline $\begin{array}{l}\text { Discuss politics face- } \\
\text { to-face }\end{array}$ & $0.20^{\star *}(0.06)$ & $0.12^{*}(0.06)$ & $0.17^{\star *}(0.05)$ & $0.10^{*}(0.06)$ & $0.20^{\star *}(0.06)$ & $0.07(0.08)$ \\
\hline politics online & 6) & & 5) & & 0. & 08) \\
\hline Politic & 0.22 & & 0.2 & & $0.13^{\star \star}(0$ & $0.13^{\star \star}$ \\
\hline TV or ra & $0.15^{\star \star}(0.04)$ & 0. & 0.0 & & $0.06(0$ & 0.08 \\
\hline $\begin{array}{l}\text { Print newspaper or } \\
\text { magazines }\end{array}$ & $-0.21^{* *}(0.06)$ & $-0.22^{\star *}(0.08)$ & $-0.11^{\star *}(0.04)$ & $-0.04(0.07)$ & $-0.14^{\star *}(0.07)$ & $-0.16^{\star}(0.08)$ \\
\hline $\begin{array}{l}\text { Social media news } \\
\text { (e.g., Twitter) }\end{array}$ & $0.05(0.05)$ & $0.10^{*}(0.05)$ & $0.03(0.04)$ & $0.04(0.05)$ & $-0.01(0.05)$ & $-0.01(0.06)$ \\
\hline $\begin{array}{l}\text { News from blog or } \\
\text { Youtube posts }\end{array}$ & $-0.19^{* *}(0.00)$ & $-0.21^{\star *}$ & .06) & 08) & $-0.03(0.07)$ & $-0.12(0.08)$ \\
\hline Observations & 613 & 590 & 843 & 762 & 701 & 612 \\
\hline
\end{tabular}

${ }^{\star *} p<0.05 ;{ }^{*} p<0.10$

Note: OLS regression coefficients and standard errors. All variables (except age) on a 0-1 scale. Suppressed coefficients include: marital status, employment status, region ( $1=$ South), and ABS sample source.

carceral violence, we find that education is not predictive for Latinos and has a weaker relationship to this domain of knowledge among African Americans and is slightly weaker for whites. Consistent with other research on political knowledge, we find that the relationship between education and knowledge is stronger for general knowledge than for domain-specific facts (e.g., Barabas et al. 2014) including knowledge about carceral violence, especially among young people of color.

Another notable finding is the effect of sex on political knowledge. Specifically, while we find evidence consistent with the well-established "gender gap" in political knowledge among whites in both domains of knowledge, the results are quite different among African American and Latino young people. First, there are no differences between men and women in traditional knowledge or knowledge of carceral violence among African Americans. ${ }^{4}$ Second, for Latinos, there are no differences between men and women in knowledge of carceral violence. These findings indicate that, (a) differences between men and women in political knowledge levels vary across race and ethnicity and (b) that knowledge of the carceral state (carceral violence) is less "gendered" (that is, there are no differences between men and women) for African Americans and Latinos.

A consistent and large predictor of political knowledge (both traditional knowledge and knowledge of police and court violence) is frequency of Internet access. Specifically, while we expected to find that young people who were regularly online would have greater knowledge of carceral violence, what we found was that young people who are online every day are much more likely to possess knowledge of both domains of politics compared to young people who use the Internet with less frequency. Notably, the effect of Internet usage on knowledge of carceral violence is limited to African Americans $(\mathrm{p}<0.05)$ and Latinos $(\mathrm{p}<0.10)$. Whites' knowledge of carceral violence does not vary as a function of Internet use. These findings provide suggestive evidence consistent with our expectation that the social media landscape promotes knowledge of carceral violence as visceral images spread online and through social networks, especially social networks among young people of color.

Indeed, one large predictor of knowledge of carceral violence for African Americans is online homophily. African Americans who mostly interact with other African 
Americans online have more knowledge about the victims of carceral violence. One possibility for this relationship is that African American friends and acquaintances are sharing videos and commentary about incidents of carceral violence. For whites and Latinos, however, online homophily decreases knowledge of carceral violence. Thus, the Internet appears to facilitate knowledge of carceral violence, but it seems to be contingent on the nature of who one is interacting with on the Internet. The extent to which the Internet acts as racial "echo chambers" such that people interact only or mostly with members of their own racial and ethnic groups may lead to polarization in domains of knowledge; increasing knowledge of carceral violence among African Americans and decreasing knowledge of this domain among whites and Latinos.

Interestingly, we find no relationship between visiting websites targeting people of color and knowledge of carceral violence among African Americans, while visiting websites targeting people of color is associated with less knowledge of carceral violence among whites (and has no effect on this domain of knowledge among Latinos). Perhaps for whites, the negative relationship is partly because (the few) whites who visit these websites are already embedded in networks where such stories are already being discussed. ${ }^{5}$ We expected that websites targeting people of color would include content about carceral violence against people of color more than other websites, leading to increased knowledge. This in fact may be the case, but it seems that those who are visiting such websites are not more likely to have knowledge of carceral violence, all else equal. It may be that commentary and images about police and court violence are so widely circulated in African American networks that one does not need to visit a website targeting people of color to access that material. Furthermore, websites targeting people of color is a broad category that could include material highlighting political and social issues but also cultural, economic, and entertainment content.

While visiting websites targeting people of color is not associated with higher levels of knowledge of police and court violence for African Americans, there is a positive relationship between this domain of knowledge and getting political news from social media. Again, news from social media is associated with higher levels of knowledge about carceral violence only for African Americans and has no effect for Latinos or whites. This suggests that carceral violence is an issue and domain of knowledge particularly relevant to African American young people and, possibly, one that they discuss and then learn about through online social interactions.

In summary, these findings, though based only on cross-sectional data and therefore preventing us from making any causal claims, provide suggestive evidence that the digital media landscape may serve as a vehicle for learning about carceral violence, especially among African
Americans who are enmeshed in online peer networks and appear to get information about carceral violence from their social networks. Given that carceral violence disproportionately affects African Americans, we expected and find that online interactions are associated with heightened knowledge of state violence more among African Americans than other racial and ethnic groups. Indeed, online homophily and getting political news from social networks predict African Americans'-but not whites' or Latinos'-increased knowledge levels of carceral violence.

A second broad finding is that there are important differences between the traditional knowledge battery and knowledge of carceral violence in terms of their correlates. Education, sex, and political interest/discussion are all more strongly predictive of traditional political knowledge than knowledge of carceral violence. These findings suggest that there are distinct pathways to acquiring knowledge of carceral violence from general political knowledge.

\section{Political Correlates of Two Kinds of Political Knowledge}

Our final analysis examines the correlates of these two types of knowledge on political attitudes and behavior. We focus in particular on five variables modeled as dependent variables: (1) linked fate (Dawson 1995); ${ }^{6}$ (2) internal and (3) external efficacy; (4) voting; and (5) taking part in a protest, demonstration, or sit-in. Again, we anticipate that both types of knowledge are politically meaningful and that they will have independent and distinct relationships with these political variables. Moreover, we hypothesize that knowledge about carceral violence will be associated with depressed levels of political participation and external efficacy. Table 3 presents the results of analyses from a multivariate model that includes both domains of knowledge as independent variables and controls for demographics.

Table 3 shows three clear correlates of knowledge of carceral violence among African Americans: a higher sense of linked fate with other African Americans ( $p<0.05)$, the hypothesized decrease in feelings of external efficacy (i.e., it is associated with believing that leaders in government care very little about people like themselves; $\mathrm{p}<0.05$ ), and as predicted a decreased likelihood of participating in protest activity $(\mathrm{p}<0.05)$. African American young people who know about the violent arm of the state are less politically active, consistent with previous studies that suggest aggressive policing and criminalization will decrease participation of those directly and indirectly effected (Burch 2013; Lerman and Weaver 2014).

For young Latinos, we find that knowledge of carceral violence is also negatively associated with external efficacy $(\mathrm{p}<0.05)$ and protest activity $(\mathrm{p}<0.10)$, such that Latinos who know more about victims of state violence have lower 
Table 3

Political correlates of traditional and carceral violence political knowledge

\begin{tabular}{|c|c|c|c|c|c|c|}
\hline & \multicolumn{2}{|c|}{ African Americans } & \multicolumn{2}{|c|}{ Whites } & \multicolumn{2}{|c|}{ Latinos } \\
\hline & $\begin{array}{l}\text { Traditional } \\
\text { Knowledge }\end{array}$ & $\begin{array}{c}\text { Knowledge } \\
\text { of Carceral } \\
\text { Violence }\end{array}$ & $\begin{array}{l}\text { Traditional } \\
\text { Knowledge }\end{array}$ & $\begin{array}{c}\text { Knowledge } \\
\text { of Carceral } \\
\text { Violence }\end{array}$ & $\begin{array}{l}\text { Traditional } \\
\text { Knowledge }\end{array}$ & $\begin{array}{l}\text { Knowledge } \\
\text { of Carceral } \\
\text { Violence }\end{array}$ \\
\hline Linked Fate & $0.19^{\star \star}(0.07)$ & $0.16^{\star \star}(0.06)$ & $0.28^{\star \star}(0.06)$ & $0.05(0.05)$ & $0.08(0.06)$ & $0.06(0.06)$ \\
\hline $\begin{array}{l}\text { Internal } \\
\text { Efficacy }\end{array}$ & $0.09^{*}(0.05)$ & $-0.07(0.05)$ & $0.27^{\star *}(0.04)$ & $0.04(0.04)$ & $0.20^{\star \star}(0.05)$ & $-0.01(0.04)$ \\
\hline $\begin{array}{l}\text { External } \\
\text { Efficacy }\end{array}$ & $-0.05(0.05)$ & $-0.11^{\star \star}(0.05)$ & $-0.14^{\star \star}(0.05)$ & $-0.05(0.04)$ & $-0.16^{\star \star}(0.04)$ & $-0.09^{\star \star}(0.04)$ \\
\hline Voting & $0.25^{\star \star}(0.11)$ & $-0.07(0.10)$ & $0.34^{\star \star}(0.11)$ & $0.24^{* *}(0.09)$ & $0.31^{* *}(0.11)$ & $-0.01(0.10)$ \\
\hline Protest & $0.05(0.037)$ & $-0.12^{\star \star}(0.053)$ & $0.03(0.044)$ & $0.04(0.043)$ & $0.01(0.038)$ & $-0.06^{*}(0.037)$ \\
\hline
\end{tabular}

${ }^{\star \star} p<0.05 ;{ }^{*} p<0.10$

Note: OLS regression coefficients with linearized standard errors in parentheses. Coefficients are suppressed for education, age, sex, language of survey, marital status, employment status, South, and sampling frame

beliefs that leaders in government care about people like them and are also less likely to participate in protest activity. For young whites, knowledge of carceral violence has different associations with these outcome variables. Specifically, greater knowledge of carceral violence is associated with higher rates of voting $(\mathrm{p}<0.05)$, but does not affect perceptions of external efficacy or protest behavior. It might be the case that while knowledge of carceral violence confirms for people of color their belief that the carceral state is out to get them, for young whites this might be new information about another domain of state activity that motivates them to participate, believing that such activity might lead to changes in state behavior.

Overall, these findings suggest that knowledge of carceral violence has different relationships with political attitudes and behaviors across racial and ethnic groups: for young people of color, knowledge about instances of state violence against people like them is associated with increased skepticism towards government and decreased engagement in protest activity. Young African Americans with this knowledge also have a stronger sense of linked fate with other African Americans as a group. However, young whites who possess knowledge of state violence against people of color do not differ from whites without this information in their beliefs about the efficacy of government or protest activity; instead, for whites this knowledge is associated with greater voting participation perhaps by raising awareness about racism and racial injustice. We also did the analysis with an eye toward how the findings might differ by sex for the categories of men and women and, in general, there were no differences.

Overall, the findings suggest that different forms of knowledge are correlated with different forms of activity. Like in previous research, we find that measures of traditional knowledge are correlates of voting behavior across race and ethnicity. Thus, if scholars want to understanding the voting behavior of young people, they would do well to include measures of traditional political knowledge in their models. If, however, they are interested in a range of political attitudes and behaviors, in particular of communities of color, including those that are more likely to result in direct and sometimes confrontational interactions with the state, such as protest, then measures of the carceral face of the state should be a part of their analysis.

\section{Conclusion}

What is political knowledge? At the outset, we introduced a definition from Delli Carpini and Keeter (1996) of political knowledge as political facts stored in long term memory. We think this definition is appropriate, but that we need to broaden the conception of what politics is, and for whom. The American state is broader than just the formal "rules of the game, ... people and parties" as Delli Carpini and Keeter (1996, 294) put it. These are important elements of American politics, no doubt, but they do not fully encapsulate the mechanisms of state power and influence. Yet these are the types of facts that most scholars, of both general and domainspecific knowledge, have largely considered in their models of political knowledge. We show that, particularly if we want to understand the political experiences, beliefs, and engagement of groups that often experience the state as a threat-which is too often the case for African American youth in particular-we need to expand the set of facts we ask about to include the coercive side of the state, which includes knowledge about victims of carceral violence.

Through a unique battery of questions about the victims of carceral violence, we begin to uncover knowledge about the carceral state. We show, first, that group-differences in 
levels of political knowledge are reversed when measuring knowledge of carceral violence: African Americans know more about victims of carceral violence than whites and Latinos. By contrast, our data on traditional knowledge was consistent with past findings: Whites know more about the rules, people and institutions, i.e., the liberal-democratic face of the state, than African Americans and Latinos. Second, people who can identify victims of carceral violence are not necessarily experts on other facts of institutional American politics; similarly, those with high levels of socalled "general" political knowledge are not especially effective at identifying victims of the carceral state. Consistent with research on issue publics, generalist static knowledge about politics does not lead to expertise on all aspects of politics, and there exist other dimensions where issue publics emerge to acquire information that is particularly relevant to them or their community. Third, we showed that the social media landscape is correlated with increased knowledge of carceral violence, particularly for African Americans, and that knowledge of carceral violence has different correlates from the traditional political knowledge battery, such as smaller or no differences between men and women. Finally, we found that knowledge of carceral violence has unique relationships with political attitudes and behavior: associated with reduced feelings of external efficacy and lower engagement in protest activity among African Americans and Latinos, a heightened sense of linked fate among African Americans, and greater self-reported voter turnout among whites.

We believe that these findings provide a number of important contributions to scholarship on political knowledge, public opinion, and racial and ethnic politics. But we would also note some limitations. In particular, our analysis is limited to a feature of the carceral state most experienced by African Americans: negative and violent interactions with the police and courts. But the carceral state is more expansive than just the police and courts and includes other dimensions and actors such as immigration authorities, and victims from other racial, ethnic, and marginal communities. It is possible that a more expansive conception and measure of knowledge of carceral state power would uncover additional findings about group differences in political knowledge levels. In particular, we might expect that immigrant communities would represent an issue public that possesses the most knowledge of immigration authorities or victims of carceral violence against immigrants given that these communities are often targeted and face threats in the ongoing fight over immigration in the United States. In addition, our analysis focuses on racial/ethnic differences in these two types of political knowledge. Yet there may be differences in correlates of knowledge of carceral violence across categories of sex, class, or education. Applying an intersectional lens to knowledge of the carceral state and examining knowledge of the carceral state as it affects immigrant communities represent two prominent areas for future research.
Given both the growing diversity of the American population and the continued salience of carceral violence as a political issue, our findings suggest that previous measures of political knowledge will lead to incorrect and biased assessments about overall levels of political knowledge and group-differences in knowledge levels. In particular, a focus only on traditional or general knowledge questions would lead to the erroneous conclusion that African Americans youths and young adults are less informed than young whites. Our findings suggest that is not the case; young whites and African Americans are not differentially informed, but instead they possess different types of information. Furthermore, given the correlation we found between knowledge of carceral violence and political outcomes, the increasing spread of this information online has the potential to shape young adults' views of government, their sense of identity, and their level of political engagement. These findings indicate that knowledge of carceral violence is and will continue to be a fundamental feature of young Americans'-particularly young black Americans'-political socialization and experience. Thus, to fully understand public opinion and political behavior, especially the public opinion and political behavior of people of color, scholars need to be cognizant of the ways interactions with and knowledge of the state varies by race and ethnicity.

\section{Supplemental Material}

Appendix A. Question Wording

Appendix B. Supplementary Analyses

To view supplementary material for this article, please visit https://doi.org/10.1017/S1537592718003857

\section{Notes}

1 For more information on the Youth and Participatory Politics survey please visit https://ypp.dmlcentral.net/ projects/youth-participatory-politics-survey-project.

2 We share the concern that online measures of political knowledge may contain some amount of "cheating" (Clifford and Jerit 2016). However, given that both sets of questions were asked in an identical survey mode, we believe that concerns over the validity of comparisons across measures are minimal.

3 The difference between African Americans and Latinos in traditional knowledge is marginally significant $(\mathrm{p}<0.10)$.

4 This is also true when we analyze knowledge of male and female victims of carceral violence separately.

5 Indeed, a bivariate analysis shows no relationship between visiting websites for people of color and knowledge of carceral violence among whites.

6 We present the results for all groups but note that the measure of linked fate may only be applicable to African Americans (Dawson 1995). 


\section{References}

Abrajano, Marisa. 2014. "Reexamining the 'Racial Gap' in Political Knowledge." Journal of Politics 77(1): 44-54. Abramson, Paul R. 1977. The Political Socialization of Black Americans: A Critical Evaluation of Research on Efficacy and Trust. New York: Free Press.

Barabas, Jason, Jennifer Jerit, William Pollock, and Carlisle Rainey. 2014. "The Question(s) of Political Knowledge.” American Political Science Review 108(4): 840-55.

Barber, James David. 1973. Citizen Politics. 2d ed. Chicago: Markham Publishing.

Beckett, Katherine and Naomi Murakawa. 2012. "Mapping the Shadow Carceral State: Toward an Institutionally Capacious Approach to Punishment." Theoretical Criminology 16(2): 221-44.

Boninger, David S., Jon A. Krosnick, Matthew K. Berent, and Leandre R. Fabrigar. 1995. "The Causes and Consequences of Attitude Importance." In Attitude Strength: Antecedents and Consequences, ed. Richard E. Petty and Jon A. Krosnick, Mahwah, NJ: Lawrence Erlbaum, 159-190.

Brown, Susan K. and Frank D. Bean. 2016. "Migration Status and Political Knowledge among Latino Immigrants." RSF: The Russell Sage Foundation Journal of the Social Sciences 2(3): 22-41.

Burch, Traci. 2013. Trading Democracy for Justice: Criminal Convictions and the Decline of Neighborhood Political Participation. Chicago: University of Chicago Press.

Clifford, Scott and Jennifer Jerit. 2016. "Cheating on Political Knowledge Questions in Online Surveys: An Assessment of the Problem and Solutions." Public Opinion Quarterly 80(4): 858-87.

Cohen, Cathy J. 2010. Democracy Remixed: Black Youth and the Future of American Politics. New York: Oxford University Press.

Cohen, Cathy J. and Joseph Kahne. 2011. "Participatory Politics. New Media and Youth Political Action." Retrieved August 2, 2018. (https://ypp.dmlcentral.net/ sites/default/files/publications/Participatory_Politics_ Report.pdf).

Converse, Philip E. 1964. "The Nature of Belief Systems in Mass Publics." In Ideology and Discontent, ed. David E. Apter. New York: Free Press.

Cramer, Katherine J. and Benjamin Toff. 2017. "The Fact of Experience: Rethinking Political Knowledge and Civic Competence." Perspectives on Politics 15.3: 75470.

Dawson, Michael C. 1995. Behind the Mule: Race and Class in African-American Politics. Princeton, NJ: Princeton University Press.

Delli Carpini, Michael X. and Scott Ketter. 1993. "Political Knowledge: Putting First Things First." American Journal of Political Science, 37(4): 1179-1206.
1996. What Americans Know about Politics and Why It Matters. New Haven, CT: Yale University Press.

Dolan, Kathleen. 2011. "Do Women and Men Know Different Things? Measuring Gender Differences in Political Knowledge." Journal of Politics 73(1): 97-107.

Gilens, Martin. 2001. "Political Ignorance and Collective Policy Preferences." American Political Science Review 95(2): 379-96.

Greenberg, Edward S. 1970. "Black Children and the Political System.” Public Opinion Quarterly 34(3): 333-45.

Griffin, John D. and Patrick Flavin. 2007. "Racial Differences in Information, Expectations, and Accountability." Journal of Politics 69(1): 220-36.

Hayward, Clarissa Rile. 2013. How Americans Make Race: Stories, Institutions, Spaces. New York: Cambridge University Press.

Hutchings, Vincent L. 2001. "Political Context, Issue Salience, and Selective Attentiveness: Constituent Knowledge of the Clarence Thomas Confirmation Vote." Journal of Politics 63(3): 846-68.

Iyengar, Shanto. 1990. "Shortcuts to Political Knowledge: The Role of Selective Attention and Accessibility." In Information and Democratic Processes, ed. J. A. Ferjohn and J. H. Kuklinski. Champapign: University of Illinois Press, 160-85.

Kim, Young Mie. 2009. "Issue Publics in the New Information Environment: Selectivity, Domain Specificity, and Extremity." Communications Research 36(2): 254-84.

. 2012. "The Shifting Sands of Citizenship: Toward a Model of the Citizenry in Life Politics." Annals of the American Academy of Political and Social Science 644: 147-58.

Krosnick, J. A. 1990. "Government Policy and Citizen Passion: A Study of Issue Publics in Contemporary America. Political Behavior 12: 59-92.

Lerman, Amy E. and Vesla M. Weaver. 2014. Arresting Citizenship: The Democratic Consequences of American Crime Control. Chicago: University of Chicago Press.

Lupia, Arthur. 2016. Uninformed: Why People Know So Little about Politics and What We Can Do About It. New York: Oxford University Press.

Luskin, Robert C. 1990. "Explaining Political Sophistication." Political Behavior 12(4): 331-61.

McGraw, Kathleen M. and Neil Pinney. 1990. "The Effects of General and Domain-Specific Expertise on Political Memory and Judgment." Social Cognition 8(1): 9-30.

Mondak, Jeffery J. and Mary R. Anderson. 2004. "The Knowledge Gap: A Reexamination of Gender-Based Differences in Political Knowledge." Journal of Politics 66(2): 492-512.

Ondercin, Heather L. and Daniel Jones-White. 2011.

"Gender Jeopardy: What Is the Impact of Gender 
Differences in Political Knowledge on Political Participation.” Social Science Quarterly 92(3): 675-94.

Pérez, Efrén O. 2015. "Mind the Gap: Why Large Group Deficits in Political Knowledge Emerge-and What to Do about Them." Political Behavior 37(4): 933-54.

Perrin, Andrew. “Social Media Usage: 2005-2015.” 2015. Pew Research Center. Retrieved August 2, 2018 (http:// www.pewinternet.org/2015/10/08/social-networkingusage-2005-2015/).

Prior, Markus. 2002. "Political Knowledge after September 11.” PS: Political Science and Politics 35(3): 523-29.

2013. "Visual Political Knowledge: A Different

Road to Competence?" Journal of Politics 76(1): 41-57. Sanbonmatsu, Kira. 2003. "Gender-related Political Knowledge and the Descriptive Representation of Women.” Political Behavior 25(4): 367-88.
Soss, Joe and Vesla Weaver. 2017. "Police Are Our Government: Politics, Political Science, and the Policing of Race-Class Subjugated Communities." Annual Review of Political Science 20(1): 565-91.

Verba, Sidney, Kay Lehman Schlozman, and Henry E. Brady. 1995. Voice and Equality: Civic Voluntarism in American Politics. Cambridge: Harvard University Press.

Weaver, Vesla M. and Amy E. Lerman. 2010. "Political Consequences of the Carceral State." American Political Science Review 104(4): 817-33.

Zaller, John. 1986. "Analysis of Information Items in the 1985 NES Pilot Study." Report to the Board of Overseers for the National Election Studies. Retrieved August 2, 2018 (https:/electionstudies.org/wp-content/uploads/ 2018/07/nes002261.pdf).

1992. The Nature and Origins of Mass Opinion.

New York: Cambridge University Press. 